\title{
Immigration and urban housing market dynamics: the case of Haifa
}

\author{
Arno J. van der Vlist • Daniel Czamanski • \\ Henk Folmer
}

Received: 7 July 2009 / Accepted: 1 April 2010 / Published online: 16 June 2010

(C) The Author(s) 2010. This article is published with open access at Springerlink.com

\begin{abstract}
This paper addresses the interplay between demographics and housing market dynamics in Haifa, Israel. In the 1990s the city of Haifa, with a population of approximately 220,000, absorbed about 45,000 immigrants. The case of Haifa offers a typical non-controlled experiment on how demographic shocks and associated changes in housing demand affect the housing market. The dynamic adjustment of house prices is estimated using an autoregressive, distributed lag ADL model, taking into account spatial spillover effects. The data analyzed cover housing transactions in Haifa between January 1989 and June 1999. The data come from a mortgage database. We used a house price index by tract and by year to investigate the impact of immigration on house price dynamics for a balanced panel of 34 tracts and 11 years. Tests showed that for some of the tracts house price series are not unit root. Most individual series though indicated that a unit root could not be rejected so that we considered house price series as being non-stationary. Also, the hypothesis of no co-integration could not be rejected by the data. Due to inertia we considered lagged spatial spillover effects for the dependent variable. We applied the corrected least squares dummy variable estimator to estimate the parameters of interest. The estimates of the coefficient of the lagged dependent variable suggest stability of the ADL structure. Furthermore, the results indicate a house price correction of almost
\end{abstract}

\footnotetext{
A. J. van der Vlist $(\varangle) \cdot$ H. Folmer

Department of Economic Geography, Faculty of Spatial Sciences, University of Groningen, Groningen, The Netherlands

e-mail: A.J.van.der.Vlist@rug.nl
}

\section{A. J. van der Vlist}

Economic Institute for Construction and Housing, Amsterdam, The Netherlands

D. Czamanski

Faculty of Architecture and Town Planning, Technion-Israel Institute of Technology, Haifa, Israel 
$70 \%$ of the gap between house prices and its fundamental determinants each year. Our results suggest a substantially faster response after the demand shock in Haifa than obtained by others for other cities and regions in the literature. Yet our estimates seem not unreasonable given the large-scale land conversion and urban construction programs in Israel and underline the importance of a responsive supply to dampen house price rises after an unanticipated demographic shock.

\section{JEL Classification R1}

\section{Introduction}

Israel experienced a large influx of immigrants during the early 1990s. Within one decade, more than one million immigrants, or almost 300,000 households arrived in the country. Within this short period of time the population rose from 4.5 to almost 6.4 million by 2000 . The city of Haifa being the third largest city in Israel was no exception. Most of the immigrants settled in the country's three big cities, namely, Haifa, Tel-Aviv, and Jerusalem (Portnov 1998). Haifa absorbed roughly 45,000 immigrants. The number of inhabitants rose to 268,000 . It is to be expected that such a large influx of immigrants affected the housing market significantly. The aim of this paper is to analyze how Haifa's housing market absorbed the demographic shock.

The case of Haifa offers a typical non-controlled experiment of the impact of demographic shocks and the associated changes in housing demand on the housing market. Figure 1 illustrates the demographic shock in 1989-1991 with annual population growth rates of nearly 10\%. After 1991 the annual growth rates flattened. However, in 1995 another, though smaller, wave of immigration took place. The right-hand side of Fig. 1 depicts the house prices changes. It depicts a sharp rise in 1989-1990 after which it the price increases flatten until 1995-1996, a period during which there is a second shock that tapers off towards 1998 when a recession hit Israel.

Alperovich (1997) is an earlier study concerned with immigration and house prices in Israel. It relates to the period between 1959 and 1988. During this period, however, the demographic shocks were much smaller and more gradual than the shocks considered here.
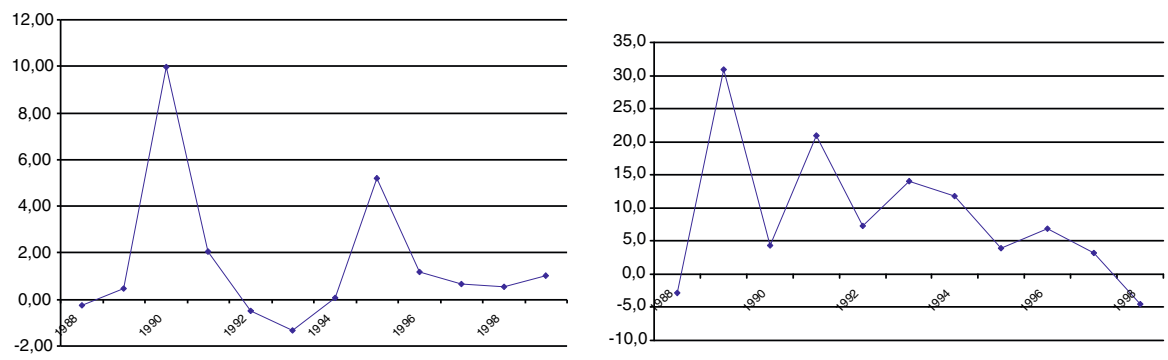

Fig. 1 Annual population growth (left) and annual average house price change (right), Haifa 1985-2000 (Source CBS.Il) 
It is natural to consider that demographics and housing markets are interrelated. The basic research questions relate to the rate of absorption of shocks and the mechanisms by which they are absorbed. Particularly, are demographic shocks absorbed through higher prices, through changes in the stock, or both? Furthermore, does the housing market return to the same equilibrium price level as prior to the shock?

The impact of demographic developments on housing markets has been subject of earlier studies. Jaffee and Rosen (1979) focused on post-war baby booms and their impacts on the housing market. Mankiw and Weil (1989) considered the impact of demographics on housing markets in the US. Their research initiated a couple of subsequent papers for Canada (Engelhardt and Poterba 1991) and for Japan (Ohtake and Shintani 1996). Mankiw and Weil (1989) find that demographic shocks lead to higher house prices. Engelhardt and Poterba (1991) question this result on the basis of their finding that at least in Canada the adjustment mechanism is distinctly different. Holland (1991), Swan (1995) and Ohtake and Shintani (1996) question the modelling approach by Mankiw and Weil and point out an incorrect handling of time series properties, particularly, non-stationarity of the series. Ohtake and Shintani find that demography and housing stock are co-integrated on the basis of which they formulate an error correction model for house price development in Japan. Their results suggest that demographics have a significant effect on housing prices in the short run, but not in the long run. Error correction models have been estimated for the UK and the USA as well (see Hort 1998 or Meen 2001). Their results suggest long-run adjustment through the housing stock and adjustment through prices in the short-run.

These studies have significant policy relevance. They suggest repercussions for households entering the housing market. New households may encounter great difficulties to obtain affordable shelter and may experience great price risks in subsequent years (cf. Muellbauer and Murphy 1997; Ortalo-Magné and Rady 1999). As such, the results may call for active government intervention to provide affordable housing, now and in the future. The demographic shock in Haifa considered in this paper differs from previous demographic shocks analyzed in that it is large, sudden, incidental and unanticipated. This type of shock has not been analyzed before.

DiPasquale and Wheaton (1994) show that demand shocks may result in an overshooting of house prices and a gradual adjustment towards long-run equilibrium as new construction occurs. On the basis of these results, we expect that a large influx of immigrants increases the demand for housing, leading initially to higher house prices and subsequently to higher land conversion rates and housing supply that will dampen housing prices (DiPasquale and Wheaton 1994; Hwang and Quigley 2006). Hence, supply conditions play an important role in the functioning of local housing markets (cf. Mayer and Sommerville 2000; Van der Vlist et al. 2002; Barker 2003; Meen 2005). In the empirical part of this paper we analyze the fundamental relationship by considering whether demographics and house prices are co-integrated. Moreover, we consider the speed with which adjustment in house prices takes place.

The organization of this paper is as follows. Section 2 describes the Israeli housing market and Sect. 3 the data on which this study is based. Section 4 presents the empirical model and Sect. 5 the empirical results. Conclusions and directions for future research follow in Sect. 6. 


\section{Immigrants, home-ownership, and Haifa's housing market}

Israel is a country of immigrants. Over half of the Jewish population in Israel is firstgeneration immigrants, and the overwhelming majority of the other half is comprised of sons and daughters of immigrants. It is important to stress that Israel's immigration policy, unlike that in most other countries, does not stem from economic considerations. The "Declaration of Independence" of Israel (May 14, 1948) contains an explicit statement that "The State of Israel will be open to Jewish immigration and for the ingathering of the exiles". Hence, when the economic and political systems of the former USSR changed, the state of Israel opened its gates to Jewish immigrants without considering the repercussions or placing any constraints. This led to an unexpectedly large influx of immigrants who entered the housing market (Deri 2000). The Israeli government responded by initiating various programs to accommodate the immigrants. Particularly:

(a) rent assistance;

(b) government mortgages;

(c) speeded land use planning procedures;

(d) supply programs.

Rent assistance To help the immigrants, the government established a rent-assistance program offering a fixed monthly allowance to households regardless of the rented property. Many immigrants decided to co-reside, sharing a dwelling with one or two other households, bidding their joint rent allowance to the market. This strategy caused rents to rise sharply. Rents of modest dwellings doubled and even tripled (Benchetrit and Czamanski 2008). The sharp rise, however, prevented non-immigrant households to access the rental market, making them homeless and creating social disorder. Homeless families protested against the situation by putting tents in public areas in the central districts. At the climax of the crisis more than 2000 families lived in about 70 tent sites (Deri 2000).

Government mortgages To promote home-ownership the Israeli government offered cash grants and mortgages at below-market interest rates (Beenstock and Fisher 1997). Different mortgage programs were offered to young couples, singleparent families and new immigrants. The programs differed in the amount and payment conditions based on equity considerations (see Benchetrit and Czamanski 2008). Mortgages were typically granted on the basis of creditworthiness with asset value serving as collateral for the mortgage. In practice, government mortgages differed from commercial mortgages in two important respects. First, households' credit worthiness in terms of potential down payment and monthly payments was not tested. Second, they do not require official housing appraisals with asset value serving as collateral for the mortgage. The rationale for both conditions is that the vast majority of the recent immigrants neither had a steady income to finance monthly mortgage payments nor assets for substantial down payment. As a result government-mortgages may be seen as low-interest loans rather than mortgages.

Land use planning procedures To boost new construction national legislative amendments were made to enable faster land-use planning approval of construction projects, reducing the time-to-build (see Portnov 1998). The Israel Land Authority 
ILA, owning most of the land in Israel enabled faster land provision for construction (see Bar-Nathan et al. 1998).

Supply programs Several national measures were implemented to foster housing construction, both by private contractors and through government initiative. Supply programs provided incentives for construction companies (Beenstock and Fisher 1997). Also, the supply programs included reduction of the price of governmentconstructed housing.

The renewed government participation in the construction of housing constituted a reversal of trends. The Israeli government was active in the housing construction market from the state's creation until the 1970s. Its role was reduced during the 1980s (see Portnov 1998; Bar-Nathan et al. 1998). At the beginning of the immigration wave the total number of 'starts of dwelling construction' was less than 20,000 units per year, with only a few thousands of public sector 'starts of dwellings construction'. By 1991, the number of dwellings starts increased to about 84,000, with majority of dwellings starts initiated by the public sector. The government also induced private contractors to build in the poorer and more peripheral regions of the country introducing grants, bonus schemes, and buy-back guarantees (Portnov 1998; Beenstock and Felsenstein 2003). At the turn of the century, $74 \%$ of Haifa's dwelling stock was occupied by owners. Commercial renting was $20 \%$ while the remaining $6 \%$ was public renting (Hazam and Felsenstein 2007).

\section{Data}

The data analyzed covers housing transactions by spatial unit, i.e., tracts in Haifa between January 1989 and June 1999 and come from a mortgage database. The data set includes information on the date of transaction, transaction price, mortgage type, size of the apartment, and location.

Haifa is segmented into statistical areas viz., 9 quarters, 28 sub-quarters and 95 tracts. About half of the population is concentrated in the east/south (quarters 4, 5, and 9). Most of Haifa's housing stock consists of multi-apartment buildings. There are detached buildings in the southern part of Haifa (quarter 9) (see also Plaut and Plaut 1998). We use location-based data with socio-economics characteristics to complement the transaction data. For that purpose we make use of the 1995 census by the Israel Central Bureau of Statistics, CBS, and in particular socio-economic scores by statistical area. The characteristics range from 5 (low) to 20 (high). Haifa's average socio-economic score is above national average.

The sample includes 7,264 transaction records, which is about a quarter of the dwelling transactions in Haifa over the period January 1989-June 1999 (Benchetrit and Czamanski 2008). The transactions relate to eight quarters (not included is the industrial quarter 2), 19 sub-quarters and 40 tracts. To base house prices by tract on sufficiently large numbers of transactions for each and every year of observation, we aggregated some tracts resulting in 34 tracts. The data set is a balanced panel made up of 34 tracts and 11 years which gives a total of 374 observations. In Table 1 we provide information on the number of transactions by sub-market.

The dependent variable in our study is a housing price index, by tract and by year. It is noteworthy that the price index by tract is made of prices of different dwellings 
Table 1 Transactions by sub-market

\begin{tabular}{llllll}
\hline Sub-market label & 1 & 2 & 3 & 4 & Total \\
\hline Description & Low & Low-medium & Medium-high & High \\
Socio-economic clusters & $5-8$ & $9-12$ & $13-16$ & $17-20$ \\
Number of tracts & 5 & 7 & 8 & 14 & 34 \\
Total transactions in the sample & 1,341 & 2,900 & 1,426 & 1,597 & 7,264 \\
Transactions financed with & 81 & 73 & 51 & 29 & 60 \\
$\quad$ governmental mortgage (in \%) & & & & & \\
\hline
\end{tabular}

Table 2 Summary statistics

\begin{tabular}{|c|c|c|c|c|c|}
\hline & \multicolumn{4}{|c|}{ Sub-market } & \multirow[t]{2}{*}{ POOLED } \\
\hline & 1 & 2 & 3 & 4 & \\
\hline \multicolumn{6}{|l|}{ NISM2 } \\
\hline Mean price per square meter & 1,251 & 1,668 & 2,106 & 2,661 & 2,056 \\
\hline (NIS/M2) & (379) & $(351)$ & $(366)$ & $(696)$ & $(773)$ \\
\hline \multicolumn{6}{|l|}{ M2 } \\
\hline \multirow[t]{2}{*}{ Apartment size (M2) } & 75.2 & 76.5 & 84.7 & 111.6 & 91.9 \\
\hline & $(11.7)$ & $(6.7)$ & $(8.6)$ & $(32.2)$ & $(27.5)$ \\
\hline \multicolumn{6}{|l|}{ MORTGAGE } \\
\hline $\begin{array}{l}\text { Transactions financed with } \\
\text { government mortgage (share) }\end{array}$ & 0.84 & 0.74 & 0.53 & 0.34 & 0.57 \\
\hline \multicolumn{6}{|l|}{ BUILD } \\
\hline \multirow[t]{2}{*}{ Building starts Haifa (number) } & & & & & 1,288 \\
\hline & & & & & $(429)$ \\
\hline \multicolumn{6}{|l|}{ STOCK } \\
\hline \multirow[t]{2}{*}{ Housing stock Haifa (number) } & & & & & 104,869 \\
\hline & & & & & $(4,368)$ \\
\hline \multicolumn{6}{|l|}{ POP } \\
\hline \multirow[t]{2}{*}{ Population Haifa (number) } & & & & & 253,527 \\
\hline & & & & & $(12,924)$ \\
\hline$N$ & 5 & 7 & 8 & 14 & 34 \\
\hline$N T$ & 55 & 77 & 88 & 154 & 374 \\
\hline
\end{tabular}

over time. To account for heterogeneity due to unobserved housing characteristics we created a housing price index by converting NIS house prices into a house price per square meter (NISM2). ${ }^{1}$ Table 2 gives details of the sample.

1 To check the adequacy of NISM2 to account for heterogeneity we applied a hedonic approach regressing NISM2 house price on a polynomial of M2 and year dummies by tract. The adjusted R2 ranges from 40 to $65 \%$ of total variation in NIS house price depending on the specification. On the basis of this result we decided to use NISM2 as house price index. 

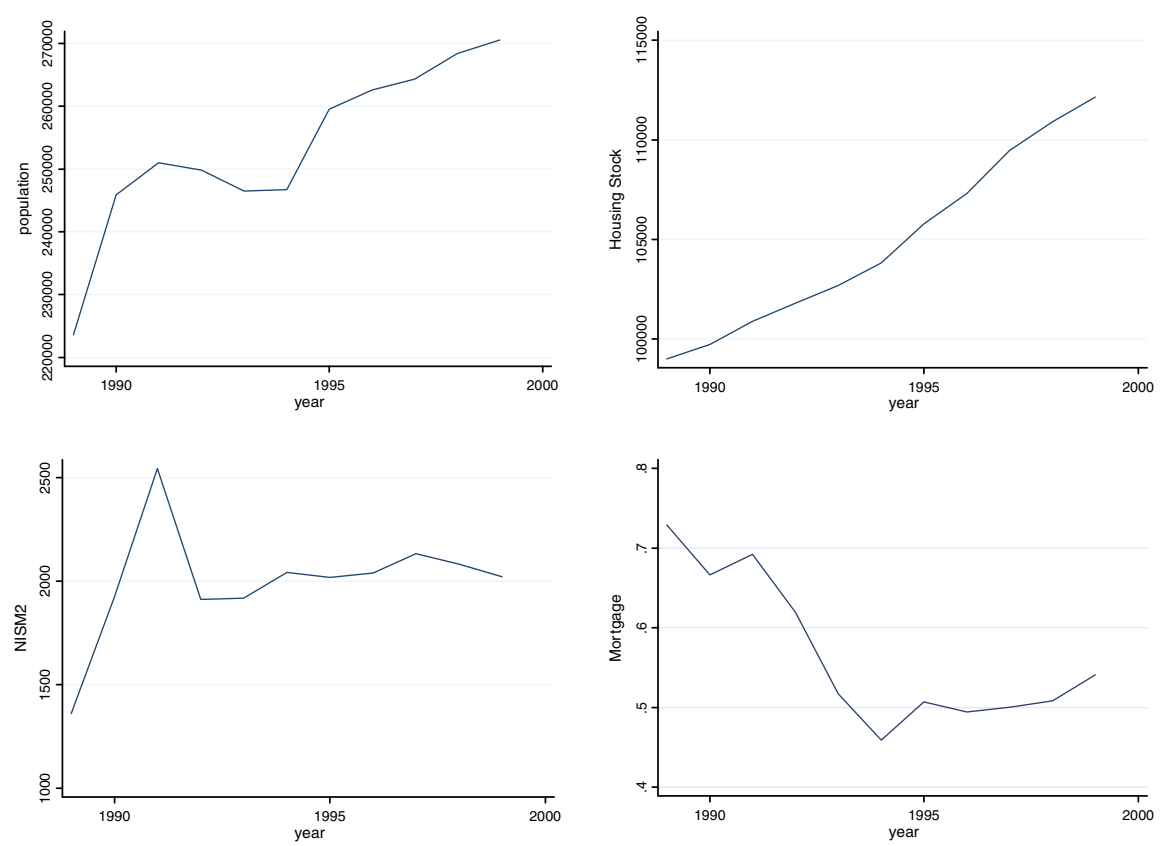

Fig. 2 Time series of population, housing stock, NISM2 and mortgage

The time series of the variables of interest are depicted in Fig 2. Observe the sharp rise in the population and the associated rise in the house price index in the early 1990s. Also note the steady increase in the housing stock throughout these years.

\section{The model}

The issue we address is whether there is a ripple effect over time such that after the influx of immigrants in the early 1990s, house prices first rise and then tail off. The rationale is as follows. The large influx of immigrants looking for shelter shifts housing demand upward, leading to a sharp house price rise as supply cannot respond instantaneously. Rising house prices typically above construction costs induces real estate developers to start new construction. The supply of new houses will make prices resettle at a new equilibrium with a larger housing stock. Thus, there are house price corrections over time (DiPasquale and Wheaton 1994).

The Israeli government intervened on the demand and on the supply side through government mortgages and construction programs, respectively. The mortgage program facilitated improved access to credit markets for immigrants and may have affected house prices in the early 1990s. Meen (2001) argues that credit constraints or mortgage rationing typically affect low-income households like most immigrants. The government mortgage programs enabled immigrants to buy dwellings in the lower end of the housing market. Thus, the proportion of transactions financed with government mortgages is an indication of how credit markets affect house prices (see also OrtaloMagné and Rady (1999). The influx of immigrants also provides an economic rent to 


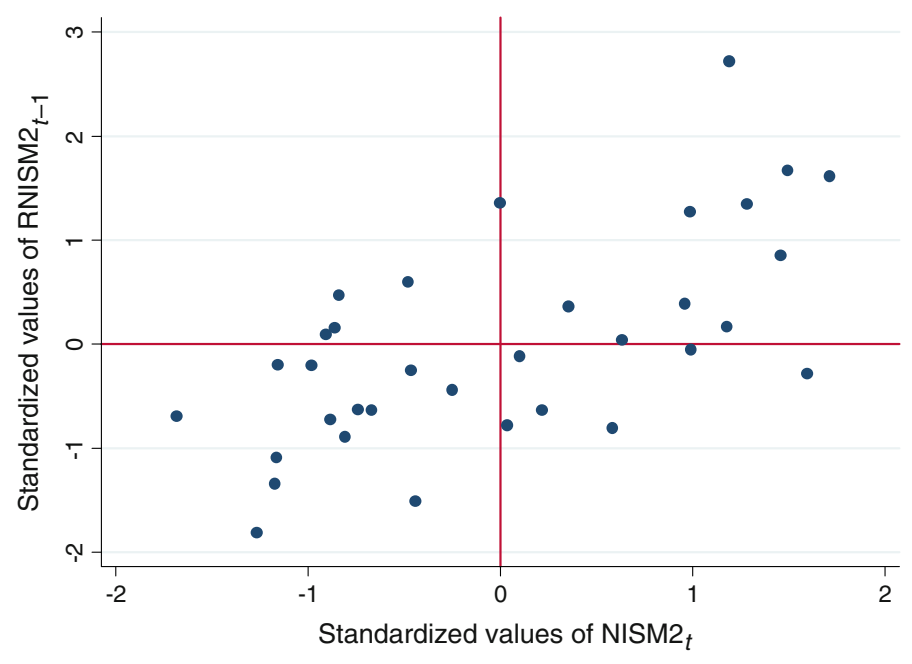

Fig. 3 Moran scatter plot of standardized values of NISM2 $2_{t}$ and RNISM2 $2_{t-1}, 1994$

owners in the lower-end sub-markets, which induces them to sell their properties to the immigrants and create demand in the higher-end housing market. Thus there are shocks at all levels of the housing market but not necessarily at the same time and of the same magnitude (see also Lipschitz 1997). Within local housing markets prices of houses may be similar because submarkets contain substitutes (see Bourassa et al. 2007). Also, observe that inertia with respect to spatial spillover is likely. We model spatial spillover using a spatial lag dependence modeling framework. LeSage and Pace (2009) argue that compared to spatial error models spatial dependence models produce unbiased estimates for a much wider range of data generating processes, as it reduce the risk of omitted variable bias in the parameters of interest.

The model we are considering is presented in Eq. (1). It describes the logarithm of the house price index per square meter (NISM2) in tract $i=1,2, \ldots, N$ at time $t=1,2, \ldots, T$ as a function of its one-period lag, spillover from first-order contiguous quarters, i.e. the logarithm of the unweighted average of the house price in first-order contiguous quarters (RNISM2), the logarithms of the current and one period-lagged population size of Haifa (POP), the logarithm of housing stock in Haifa (STOCK), and the proportion of transactions financed with government mortgages (MORTGAGE). To account for spatial correlation we include RNISM2 lagged for one year in the model. The inclusion of this variable is supported by the scatter plot of standardized values of NISM $2_{t}$ and RNISM $2_{t-1}$ for 1994 presented in Fig $3 .{ }^{2}$ Formally, the spatiotemporal autoregressive model of house prices reads:

$$
\begin{aligned}
\log \mathrm{NISM}_{i t}= & \gamma_{1} \log \mathrm{NISM}_{i, t-1}+\beta_{1} \log \mathrm{RNISM}_{i, t-1} \\
& +\beta_{2} \log \mathrm{POP}_{t}+\beta_{3} \log \mathrm{POP}_{t-1}+\beta_{4} \log \mathrm{STOCK}_{t} \\
& +\beta_{5} \mathrm{MORTGAGE}_{i t}+\alpha+\varepsilon_{i t} .
\end{aligned}
$$

\footnotetext{
${ }^{2}$ For the other years a similar relationship holds.
} 
For the autoregressive parameter the inequality $\left|\gamma_{1}\right|<1$ is assumed to hold. If this inequality holds the system is stable. The error terms $\varepsilon_{i t}$ are assumed $i i d\left(0, \sigma_{\varepsilon}^{2}\right)$. The parameter $\gamma_{1}$ indicates the proportion of NISM2 in the previous period maintained at time $t$ with $\gamma_{1}-1$ the speed of return.

The lagged dependent variable in Eq. (1) is by construction correlated with the fixed effects which renders the standard least squares dummy variable method (LSDV) inconsistent (see Davidson and MacKinnon 1993; Baltagi 1995). The literature suggests several alternative estimators conditional on the structure in the data, such as the magnitude of the autoregressive parameter $\gamma_{1}$, and the magnitudes of $N$ and $T$ (Blundell and Bond 1998). Arellano and Bond (1991) propose a linear generalized method of moments (ABGMM) estimator in which instruments are used on the basis of first differences. ABGMM is consistent if there is no second-order serial correlation after first-differencing (see Arellano and Bond 1991; Baltagi 1995). In panel data with higher orders of serial correlation the moment conditions of the ABGMM are invalid. Also, with $\left|\gamma_{1}\right|$ close to unity lagged levels become weak instruments such that ABGMM performs poorly. Blundell and Bond (1998) present an alternative system-GMM estimator that imposes further restrictions using additional moment conditions. Biased-corrected LSDV (LSDVC) has been proposed also (see Kiviet 1995).

Most of these estimators typically are for large $N$ and $T$. Judson and Owen (1999) present rules of thumb to practitioners of what estimator to use in applications. They recommend LSDVC for balanced panels and GMM for unbalanced panels with $T \leq 20$. Bun and Kiviet (2006) though indicate more exactly that (system) GMM estimators require $N \geq K(T-1)$, with $\mathrm{K}$ the number of regressors.

The performance of the various estimators mentioned above for fixed $N$ and $T$ has been addressed in various Monte Carlo studies, which vary in the number and detail with which estimators are considered (Kiviet 1995; Blundell and Bond 1998; Bun and Kiviet 2006). Bun and Kiviet (2006) recently indicate that in small samples none of the estimators dominates in terms of bias and mean squared error over all parameterizations. Therefore, we adopt the corrected LSDV (Bruno 2005).

\section{Empirical results}

We first address the time series properties of the variables before estimating model (1). Particularly, we tested whether house price and population series are integrated into the same order. We applied the augmented Dickey-Fuller (ADF) unit root tests and, given the short time period, experiment with 1 and 2 lags to test the null hypothesis of a unit root. We considered unit root tests for both individual series and panel data.

We first applied the panel-based unit root tests for house prices, population and stock. Results are given in Table 3. For house price the ADF panel unit root test contrary to the Hadri test do not indicate a common unit root. We also consider the properties of the time series aggregated over all tracts. The ADF test indicated a unit root for pooled NISM2. 
Table 3 Results for augmented Dickey-Fuller unit root panel test

\begin{tabular}{|c|c|c|c|c|c|c|}
\hline \multirow[t]{2}{*}{ Panel test } & \multicolumn{2}{|l|}{ NISM2 } & \multicolumn{2}{|l|}{ POP } & \multicolumn{2}{|c|}{ STOCK } \\
\hline & Fisher & $\mathrm{Ha}$ & Fisher & $\mathrm{Ha}$ & Fisher & $\mathrm{Ha}$ \\
\hline Test statistic & 553.9 & 11.9 & 4.96 & 13.74 & 31.6 & 11.26 \\
\hline$p$ value & 0.00 & 0.00 & 1.00 & 0.00 & 1.00 & 0.00 \\
\hline
\end{tabular}

Fisher augmented Dickey-Fuller test. $\mathrm{H}_{o}$ : there is unit root. One lag included; Ha: Hadri test. $\mathrm{H}_{O}$ : there is no unit root. Trend and one lag included, controlling for serial dependence in errors POP and STOCK are time series that do not vary across cross-sectional units

Table 4 Estimation results for the dynamic panel model, corrected LSDV estimates

See Table 2 for description of variables

* significant at $10 \%$;

** significant at $5 \%$

\begin{tabular}{lcc}
\hline $\log$ NISM $_{i, t}$ & Parameter & SE \\
\hline $\log$ NISM $2_{i, t-1}$ & $0.26^{* *}$ & 0.06 \\
$\log$ RNISM $_{i, t-1}$ & -0.20 & 0.07 \\
$\log$ POP $_{t}$ & $2.64^{* *}$ & 0.85 \\
$\log$ POP $_{t-1}$ & 0.71 & 0.51 \\
$\log$ STOCK $_{t-1}$ & $-2.13^{*}$ & 0.95 \\
MORTGAGE $_{i, t}$ & 0.07 & 0.06 \\
\hline
\end{tabular}

We also considered the individual house price series using ADF and Philips-Perron tests for each and every tract. The results indicated that for 16 tracts the house price series are not unit root, which is most likely due to the quality of the house price index. For the majority of the individual house price series a unit root could not be rejected. On the basis of this result and the Hadri test results, we consider the house price panel series as being non-stationary. The various tests indicate that for population the hypothesis of a unit root could not be rejected, suggesting non-stationarity of the series. Finally we addressed the housing stock series. Tests for STOCK indicated a unit root also.

We continued our analysis considering whether the house price and population series are co-integrated. We performed a panel ADF unit root test for the ratio of house price over population. The ADF test results indicated clear rejection of a unit root which is consistent with the co-integrating relationship assumed in an ADL or associated error correction model.

On the basis of the above results, we estimated model (1). The results are given in Table 4 for the panel model over all sub-markets.

The estimated coefficient of the lagged dependent variable satisfies the stability inequality specified above. Furthermore, the estimate for $\gamma$ of 0.26 , suggests a correction $(\gamma-1)$ of over $70 \%(-0.74)$ of the gap between house prices and its fundamental determinant. Our results are in line with those obtained by Harter (2004) for the US and Ohtake and Shintani (1996) for Japan, yet is much larger in magnitude. Harter finds a parameter of -0.22 , whereas Ohtake and Shintani find an estimate of -0.33 . Moreover, Malpezzi (1999) finds estimates in the range of -0.16 to -0.32 for the US, and Hort (1998) -0.36 for Sweden. The correction of more than $70 \%$ in our study 


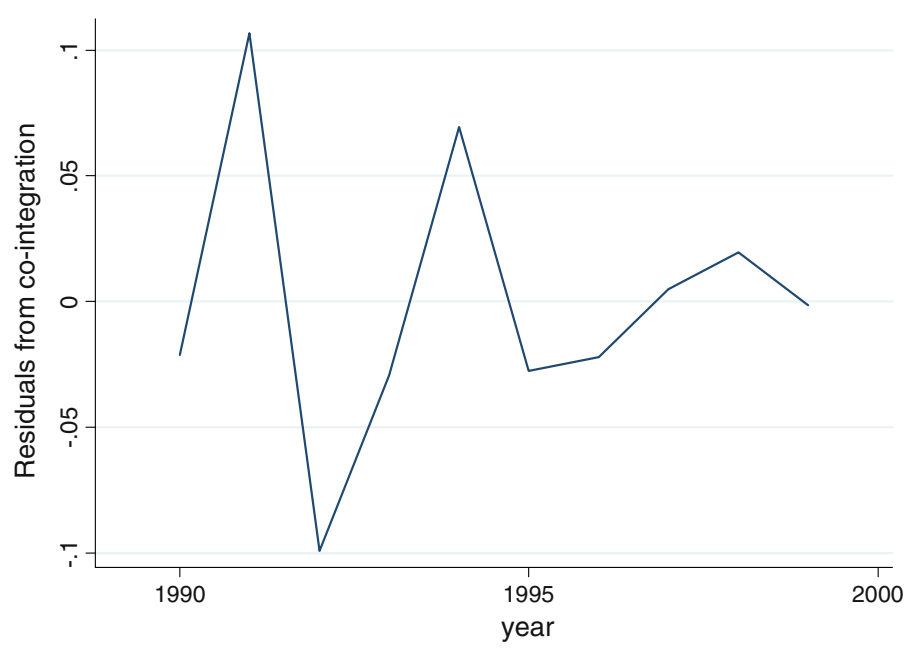

Fig. 4 Residuals from co-integration relation

is supported by the large-scale land conversion and urban construction programs in Israel.

Current population size and lagged stock have the expected signs. The parameter of the proportion of transactions financed with government mortgages, though insignificant, indicates an upward shift of $7 \%$ in house prices in Haifa (see also Schein 2002).

The residuals of the co-integrating relation give information on the degree house prices deviate from market fundamentals, i.e., the significant explanatory variables in Eq. (1). Figure 4 depicts the residuals by year reflecting the price development presented in Fig. 1. House prices typically start rising when price levels are below, and start falling when price levels are above market fundamental values, respectively. Particularly, the residuals show price levels well above $(15 \%)^{3}$ fundamentals in 1991 resulting in a substantial drop in the year after.

House prices well above market fundamentals have been related in the literature to speculative motives which in their turn may trigger retaliation by consumers (Deri 2000; Schein 2002). The sharp correction in house prices in 1992 might be due to households punishing unfair house prices, although more research is needed to measure the degree of pure mean reversion

Figure 5 presents deviations from the co-integration relationship by sub-market. The results indicate substantial differences suggesting that house price developments are local. Under-valued house prices in one sub-market typically coincide with overvalued house prices in other sub-markets indicating poor market clearness or arbitrage. Particularly, some lower-end markets indicate houses overpriced during the period.

3 Observe the log scale. 


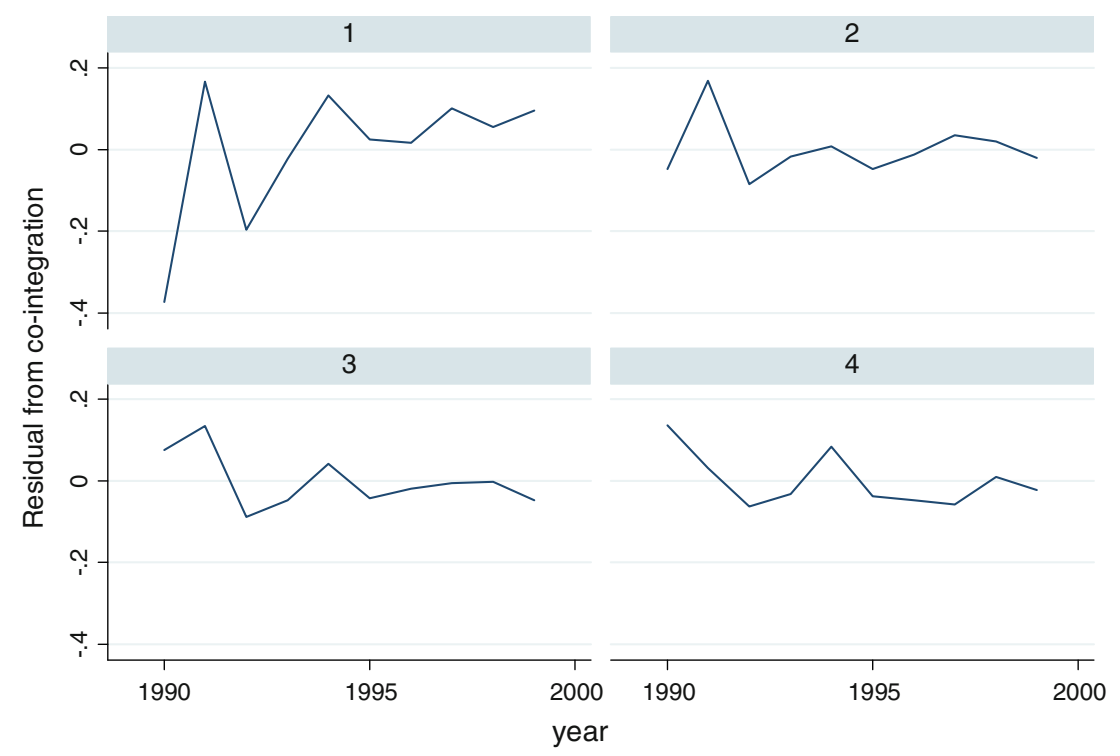

Fig. 5 Residual from co-integration relation by sub-market

\section{Conclusions}

In this paper, we considered the impact of immigration on housing market dynamics in Haifa. Israel experienced a large influx of immigrants during the early 1990s. By the turn of the century and within one decade, more than one million immigrants, or almost 300,000 households arrived in the country. Within this short period of time the population rose from 4.5 to almost 6.4 million by 2000. The case of Haifa offers a typical non-controlled experiment on how demographic shocks and associated changes in housing demand affect the housing market.

The dynamic adjustment of Haifa's house prices is modelled by means of an autoregressive, distributed lag panel model. The data analyzed cover housing transactions between January 1989 and June 1999 and come from a mortgage database. In the empirical analysis we use a house price index by tract and by year to investigate the impact of immigration on house price dynamics for a balanced panel of 34 tracts and 11 years. We use a corrected least squares dummy variable estimator to estimate the parameters of interest.

The time series test results indicated that for some of the tracts house price series are not unit root. For most of the individual series, however, a unit root could not be rejected so that we considered the house price series as being non-stationary. The population and housing stock series are non-stationary also. The co-integration test between population and house prices reject the null hypothesis of no co-integration, consistent with the proposed ADL model structure.

The estimated coefficient of the lagged dependent variable suggests stability of the ADL structure. Furthermore, the results indicate a house price correction of almost $70 \%$ of the gap between house prices and its fundamental determinant each year due 
to large-scale land conversion and urban construction programs in Israel. The cointegration residuals indicate that house prices may rise above market fundamentals giving rise to concerns about fair prices. However, more research on this issue is needed.

Acknowledgments We are grateful for helpful comments from participants in the November 2008 IsraeliDutch Regional Science Workshop, Jerusalem, the June 2009 European Real Estate Society Conference, Stockholm and the 2009 European Regional Science Association Conference Poland. Maria Marinov provided excellent research assistance.

Open Access This article is distributed under the terms of the Creative Commons Attribution Noncommercial License which permits any noncommercial use, distribution, and reproduction in any medium, provided the original author(s) and source are credited.

\section{References}

Alperovich G (1997) Israeli settlement in occupied territories and its impact on housing prices in Israel. J Reg Sci 37:127-144

Arellano M, Bond S (1991) Some tests of specification for panel data: Monte Carlo evidence of an application to employment equations. Rev Econ Stud 58:277-297

Baltagi BH (1995) Econometric analysis of panel data. Wiley, New York

Barker K (2003) Review of housing supply. Interim report. HMSO, London

Bar-Nathan M, Beenstock M, Haitovsky Y (1998) The market for housing in Israel. Reg Sci Urban Econ 29:21-49

Beenstock M, Felsenstein D (2003) Decomposing the dynamics of regional earnings disparities in Israel. Working paper. Hebrew University of Jerusalem

Beenstock M, Fisher J (1997) Macroeconomic effects of immigrants. Weltwirtschafliches Arch 133: 330-358

Benchetrit G, Czamanski D (2008) Immigration and home ownership: government subsidies and wealth distribution effects in Israel. Housing Theory and Society, pp 1-21

Blundell R, Bond S (1998) Initial conditions and moment restrictions in dynamic panel-data models. J Econom 87:115-143

Bourassa S, Cantoni E, Hoesli M (2007) Spatial dependence, housing submarkets, and house price prediction. J Real Estate Finance Econ 35:143-160

Bruno G (2005) Estimation and inference in dynamic unbalanced panel data models with a small number of individuals. Stata J 5:473-500

Bun M, Kiviet J (2006) The effects of dynamic feedbacks on LS and MM estimator accuracy in panel data models. J Econom 132:409-444

Davidson R, MacKinnon JG (1993) Estimation and inference in econometrics. Oxford University Press, Oxford

Deri D (2000) Agenda setting and problem definition. Policy Stud 21:37-47

DiPasquale D, Wheaton W (1994) Housing market dynamics and the future of housing prices. J Urban Econ 35:1-27

Engelhardt G, Poterba J (1991) House prices and demographic change: Canadian evidence. Reg Sci Urban Econ 21:539-546

Harter M (2004) Drawing inferences about housing supply elasticity form house price responses to income shocks. J Urban Econ 55:316-337

Hazam S, Felsenstein D (2007) Terror, fear and behavior in the Jeruzalem housing market. Urban Stud 44:2529-2546

Holland AS (1991) The baby boom and the housing market: another look at the evidence. Reg Sci Urban Econ 21:565-571

Hort K (1998) The determinants of urban house price fluctuations in Sweden 1968-1994. J Housing Econ 7:93-120

Hwang M, Quigley J (2006) Economic fundamentals in local housing markets: evidence from U.S. metropolitan regions. J Reg Sci 46:425-453 
Jaffee D, Rosen K (1979) Mortgage credit availability and residential construction. Brookings Papers Econ Activity 1979:333-386

Judson R, Owen A (1999) Estimating dynamic panel data models: a guide for macroeconomists. Econ Lett 65:9-15

Kiviet J (1995) On bias, inconsistency, and efficiency of various estimators in dynamic panel data models. J Econom 68:53-78

LeSage J, Pace R (2009) Introduction to spatial econometrics. Chapman \& Hall, London

Lipschitz G (1997) Immigrants from the former Soviet Union in the Israeli housing market: spatial aspects of supply and demand. Urban Stud 34:471-488

Malpezzi S (1999) A simple error correction model of house prices. J Housing Econ 8:27-62

Mankiw N, Weil D (1989) The baby boom, the baby bust, and the housing market. Reg Sci Urban Econ 19:235-258

Mayer C, Sommerville CT (2000) Land use regulation and new construction. Reg Sci Urban Econ 30: $639-652$

Meen G (2001) Modelling spatial housing markets: theory, analysis and policy. Kluwer, Dordrecht

Meen G (2005) On the Economics of the Barker Review of housing supply. Housing Stud 20:949-971

Muellbauer J, Murphy A (1997) Booms and busts in UK housing market. Econ J 107:1701-1727

Ohtake F, Shintani M (1996) The effect of demographics on the Japanese housing market. Reg Sci Urban Econ 26:189-201

Ortalo-Magné F, Rady S (1999) Boom in, bust out: young households and the housing price cycle. Eur Econ Rev 43:755-766

Plaut S, Plaut P (1998) Endogenous identification of multiple housing price centers in a metropolitan area. J Housing Econ 7:193-217

Portnov B (1998) The effect of housing on migration in Israel: 1989-1994. J Popul Econ 11:379-394

Schein A (2002) Concern for fair prices in Israel. J Econ Psychol 23:213-230

Swan C (1995) Demography and the demand for housing: a reinterpretation of the Mankiw-Weil demand variable. Reg Sci Urban Econ 25:41-58

Van der Vlist AJ, Gorter C, Rietveld P, Nijkamp P (2002) Residential mobility and local housing market differences. Environ Planning A 34:1147-1164 